\title{
Discovery of a new Steinernema sp. (Rhabditida: Steinernematidae) with higher shelf life and better efficacy against red palm weevil under laboratory conditions
}

\author{
K.M. Anes*, Merin Babu, Jinu Sivadasan and A. Josephrajkumar \\ ICAR-Central Plantation Crops Research Institute, Regional Station, Kayamkulam-690 533, Kerala, India
}

(Manuscript Received: 16-03-2020, Revised: 08-07-2020, Accepted: 01-09-2020)

\begin{abstract}
Entomopathogenic nematodes (EPN) are excellent bio-control agents for the management of insect pests of soil and cryptic habitat. One of the greatest challenges in the successful utilization of EPN is the poor shelf life of infective juveniles (IJs) under ambient temperature. The present study aimed to evaluate the survival and virulence of different EPN species for determining a superior one in the bio-suppression of red palm weevil (RPW). Among the five species of Steinernematids and two Heterorhabditid isolates evaluated, Steinernema sp. (S0804) sustained up to 13 months, with a desirable survival of 100 per cent during the first five months to about 64 per cent ten months after storage at ambient temperature. Virulence of Steinernema sp. (S0804) sustained up to ten months of storage, was confirmed using Galleria mellonella inoculation test. However, the viable IJs were observed only up to one month in both the Heterorhabditids and up to a period of four to six months of storage in all other Steinernematids. The Steinernema sp. (S0804) was also found to be efficacious against the grubs of RPW in filter paper bio-assay inducing 100 per cent larval mortality in 72 h when applied @ 200 IJs per grub and confirmed further by leaf petiole bioassay. The study thus revealed higher survival and virulence of Steinernema sp. (S0804) and also found to be a potential bio-control agent against RPW. To the best of our knowledge, this is the first EPN isolate reported, which could survive for more than one year at ambient temperature without any additives.
\end{abstract}

Keywords: Bio-control, EPN, Heterorhabditis, red palm weevil, shelf life, Steinernema

\section{Introduction}

Entomopathogenic nematodes (EPN) are lethal insect pathogens belonging to the families Steinernematidae and Heterorhabditidae, which have proved to be promising bio-control agents for the management of soil and cryptic insect pests. The developmentally arrested and non-feeding third juvenile stage known as infective juveniles (IJs), is the only survival stage in their life cycle. Soil is their natural habitat, and upon finding a suitable insect host, they enter through natural body openings or by direct penetration through the cuticle. Once IJs reach the host haemocoel, they release the symbiotic bacteria present in their intestine (Xenorhabdus for Steinernematids and Photorhabdus for Herterorhabditids), which kill the host (Kaya, 1990). They are quick in their action and induce host mortality within 24 to 48 hours of penetration. They are eco-friendly and safe towards plant or human health and are exempted from registration in many developed countries.

In India, work on Steinernematids was first initiated by Rao and Manjunath (1966) who imported DD-136 strain of Steinernema carpocapsae for use against insect pests of rice and sugarcane. Since then, several researchers have worked on exotic strains of S. glaseri (NC 34), S. feltiae and Heterorhabditis bacteriophora for managing different local insect pests. The results were inconsistent under field conditions due to their poor adaptability to the

*Corresponding Author:aneskm@gmail.com 
prevailing local environmental conditions which differed from their original place of isolation. Later, many local EPN isolates were isolated, described and reported to be effective against insect pests of local and national importance. The native isolates are well adapted to the environmental conditions of the locality and are proved to be highly effective against insect pests of native locality (Koppenhofer and Kaya, 1999).

Red palm weevil (RPW), Rhynchophorus ferrugineus Oliv., known for over a century in India, is a destructive pest of coconut and other palms throughout the country. Presently, RPW is widely distributed in Sri Lanka, Indonesia, Burma, the Philippines, Middle East, North Africa and southern Europe (Josephrajkumar et al., 2018) and observed to attack about 26 species of palms including coconut, oil palm and date palm (Malumphy and Moran, 2009). Due to the lethal nature of the pest and high value of the crop, the infestation level as low as one per cent infested palms in a plantation is assumed as action threshold (Josephrajkumar et al., 2018). Even though a wide array of potential bio-control agents is available against RPW, the present management is mainly dependent on chemical pesticides due to the lethal nature of the pest, and none of the bio-control agents is found to cause 100 per cent grub mortality which is needed for the palm recovery.

The potentiality of EPNs for the management of RPW was reported by several workers (Banu et al., 2003; Shamseldean and Atwa, 2004; Josephrajkumar et al., 2014). However, their poor shelf life is the greatest hurdle in the successful utilization of this group of bio-agents (Grewal, 2002). The influence of temperature in the survival and infectivity of EPNs is well established (Griffin, 1993; Koppenhöfer and Kaya, 1999). Long term storage of EPNs is conventionally practiced at lower temperature regimes $\left(4^{\circ} \mathrm{C}\right.$ to $\left.15^{\circ} \mathrm{C}\right)$ in aqueous suspension which enhances the survival of Steinernematids up to 6 to 9 months and in Heterorhabditids up to 3 to 4 months (Koppenhöfer, 2007). The cost involved in the cooling system during storage and transportation for maintaining the viability of EPNs makes it highly expensive (Chen and Glazer, 2005). To overcome this hurdle, the present studies are mainly focused on the development of effective formulations to enhance the survival of EPNs (Grewal, 2000). The ultimate objective of all the EPN based formulation is to enhance the storability at ambient temperature. Though the researchers were successful in developing effective formulations, the shelf life of most of these formulations varied (Kagimu et al., 2017). It is now a well established fact that a wide range of variability is present in different EPN isolates originating from different geographical regions in terms of host preference, pathogenicity or adaptation to various biotic and abiotic parameters (Bedding, 1990; Kaya, 1990). In the present study, the genetic diversity in EPNs is explored for a superior isolate with better survival at ambient temperature coupled with higher efficacy against RPW.

\section{Materials and methods}

\section{Nematode isolates}

Four Steinernematids, namely Steinernema carpocapsae (Sc), S. abbasi (Sa), S. hermaphroditum CPCRIS0905 (Sh) (GenBank Acc. No. MH802516) and Steinernema sp. CPCRIS0804 (S0804) (GenBank Acc. No. MT139646) and two Heterorhabitids, namely Heterorhabditis indica CPCRIH0701 (H0701) and H. indica CPCRIH0703 (H0703), were used in the study. Two of the isolates, $\mathrm{Sc}$ and $\mathrm{Sa}$ was originally procured from ICAR-NBAIR, and the other four were isolated locally during the last three years. The EPN isolate, Sh was recovered from the Farmer First Programme (FFP) area in Pathiyoor ( $9^{\circ} 12^{\prime} 39.348^{\prime \prime}$ $\mathrm{N} \& 76^{\circ} 29^{\prime} 44.016^{\prime \prime}$ E), Panchayath, Alappuzha district, Kerala and remaining three isolates were collected from the Research Farm of ICARCPCRI, Regional Station, Kayamkulam (9 $9^{\prime}$ 9.0864" N \& 76³0' 48.0852" E) (Anes et al., 2018). The cultures of EPNs were multiplied on fourth instar larvae of greater wax moth, Galleria mellonella and IJs were recovered using modified White's trap in Millipore water.

\section{Red palm weevil (RPW)}

Adult weevils (Rhynchophorus ferrugineus), collected from the infested palms, were used for rearing grubs in the laboratory using meridic diets (Josephrajkumar et al., 2017) and were used for the study.

\section{EPN survival}

Each culture comprising of approximately 20000 IJs in $20 \mathrm{~mL}$ Millipore water suspension was 
stored in $50 \mathrm{~mL}$ capacity vented tissue culture flasks and maintained under ambient temperature. Long duration survival study of S0804 was carried out from June 2018 to July 2019, and a comparative survival study of different EPN isolates from July 2019 to February 2020. The observations were recorded every 30 days by counting the nematode survival in $50 \mu \mathrm{L}$ suspension thrice from each sample using a Leica stereomicroscope. All the treatments were replicated thrice for the comparative survival study, and 15 replications were included in long duration survival study of S0804.

\section{Virulence of S0804 after prolonged period of storage}

The virulence of the surviving IJs of S0804 after ten months of storage was evaluated on fourth instar larvae of greater wax moth, G. mellonella. Freshly emerged IJs were also used for the study to compare the virulence after prolonged storage. The study was carried out in $5 \mathrm{~cm}$ diameter Petri plates lined with two layers of Whatman No. 1 filter paper. Three doses of both 10 months old as well as freshly emerged IJs viz., 2.5, 5 and 10 IJs per larva in 200 $\mathrm{mL}$ Millipore water suspension were the treatments and application of Millipore water without IJs served as control. Ten larvae of G. mellonella were introduced in each Petri plate. All the treatments were replicated thrice, and observations were recorded at every 12 hours.

\section{Petri plate bioassay against red palm weevil}

Bioassays were carried out to screen the best EPN isolate against RPW. The experiment was conducted in 6 well plates lined with two layers of Whatman No.1 filter paper. Millipore water $(200 \mu \mathrm{L})$ containing the desired number of IJs of respective EPNs was added in each well of the plate. The grubs were released (one grub each) in the wells after adding the respective IJs. Observations on grub mortality were recorded every 24 hours after the treatment. Initial screening was conducted using different doses viz., 100, 200 and 400 IJs per grub and each treatment were exposed to six RPW grubs. The confirmation bioassay for the selection of best isolate was carried out by treating IJs of different isolates against RPW @,200 IJs per grub.Ten grubs placed in each well of six-well plates constituted each treatment, and all the treatments were replicated thrice.

\section{Petiole bioassay}

The experiment was conducted using $15 \mathrm{~cm}$ long coconut leaf petioles. To facilitate easy observation, each petiole was split into two pieces by making a vertical cut in the centre, and then the two pieces were tied together using a rubber band. Small holes were made at one end of the petiole, and one grub was released in each petiole. Both the cut ends of the petioles were covered with an aluminium net to avoid the exit of the grubs. The treatments were superimposed after five days of releasing the grubs for perfect adaptation of grub in the new environment. Each petiole was then treated with $4 \mathrm{~mL}$ water suspension containing the desired number of infective juveniles. Observations on grub mortality were recorded five days after treatment application and continued up to two weeks.

\section{Statistical analysis}

The statistical design used was CRD, and all the percentage $(\%)$ data were transformed using arc-sine transformation and then subjected to analysis of variance. Further, least significance difference (LSD) were worked out for pairwise comparison among treatment effects and differences between treatment means were estimated at 5 per cent probability.

\section{Results and discussion}

Observations on unusual long-term survival of Steinernema sp. CPCRIS0804 were recorded at 30 days interval during the evaluation period (June 2018 to July 2019) and are presented in Figure 1. All IJs irrespective of replications were found alive for a period of five months, and a very low level of mortality was recorded during the $6^{\text {th }}$ and $7^{\text {th }}$ months of storage. The survival rate was reduced gradually from 99.8 per cent during $6^{\text {th }}$ month to 64 per cent in the $10^{\text {th }}$ month of storage. A rapid increase in the mortality rate was observed from $11^{\text {th }}$ to $13^{\text {th }}$ month of storage, mainly due to the exhaustion of nutrients from IJs. The survival was reduced to only 20 per cent during the $11^{\text {th }}$ month, 15 per cent during the $12^{\text {th }}$ month and very few IJs survived during $13^{\text {th }}$ month of storage.

A comparative evaluation on the survival of IJs of S0804 along with other five EPN isolates conducted for a period of 7 months from July 2019 to February 2020 are presented in Figure 1. 

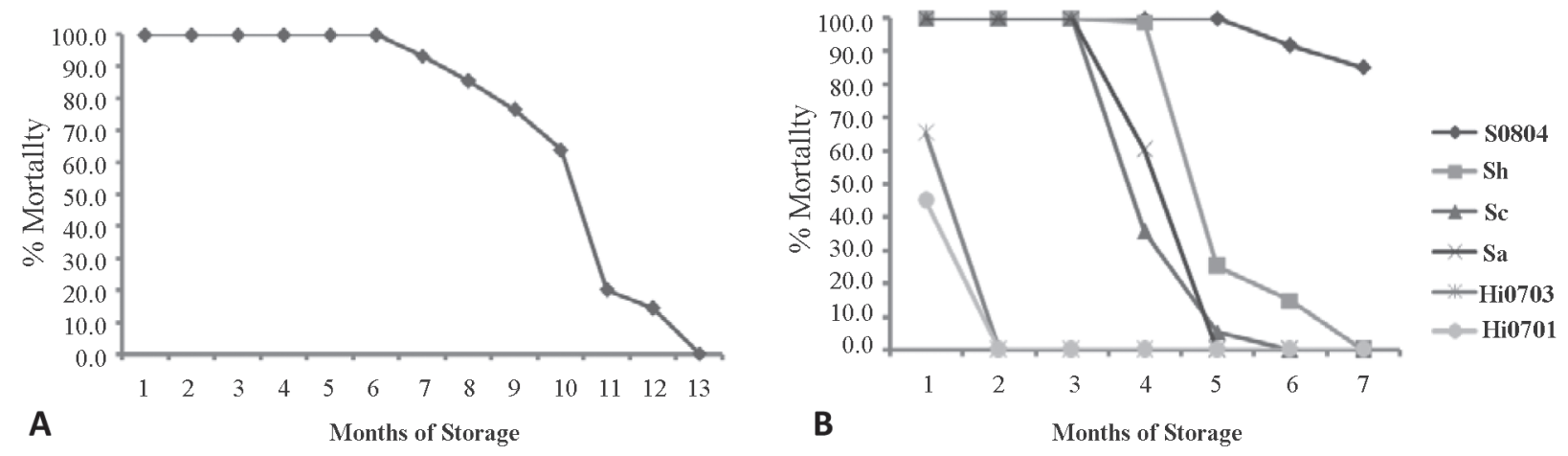

Fig. 1. Percentage survival of different EPN isolates at ambient temperature. A: Long term survival of S0804 for 13 months; B: Comparison on long term survival of different EPN isolates. (S0804: Steinernema sp. CPCRIS0804; Sh: S. hermaphroditum CPCRIS0905; Sc: S. carpocapsae; Sa: S. abbasi; Hi0701: Heterorhabditis indica CPCRIH0701; Hi0703: $H$. indica CPCRIH0703)

The IJs of all the Steinernematids survived for a longer duration compared to Heterorhabditids. Both the Heterorhabditids survived only up to one month of storage with a survival rate of 45 per cent and 65 per cent, respectively, for the strains of H0701 and H0703. In the case of Steinernematids, no mortality was observed up to $3^{\text {rd }}$ month of storage and thereafter, a gradual increase in mortality rate was recorded in all the isolates, except in S0804, where all the IJs remained alive up to 5 months of storage. IJs of Sa, Sc and Sh survived up to $4^{\text {th }}, 5^{\text {th }}$ and $6^{\text {th }}$ months, respectively. However, a drastic increase in juvenile mortality was observed after $4^{\text {th }}$ month in these Steinernematids. During the $7^{\text {th }}$ month of storage, only S0804 remained alive with the presence of 85 per cent active IJs. The study indicated the extraordinary superiority of S0804 over other EPN species in terms of survival rate or shelf life. This is mainly due to the unique energy conservation ability of S0804 compared to other strains of EPN and is not reported elsewhere.

The retention of virulence after 10 months of storage in the surviving IJs of S0804 was evaluated against fourth instar larvae of greater wax moth, G. mellonella and are presented in Table 1.

The freshly emerged IJs induced 70 to 100 per cent larval mortality within 48 hours of treatment, whereas 53 to 87 per cent larval mortality was caused by 10 months old IJs during the period. However, no significant difference was observed between the levels of larval mortality induced by freshly emerged or 10 months old IJs indicating their sustained virulence for about 10 months of storage. The larval mortality induced by 5 or 10 IJs per larva in both fresh and old IJs in all the time intervals was statistically non-significant. Even though no significant difference was observed between fresh or older IJs in the lowest dose, fresh IJs induced statistically on par mortality rate when compared to higher doses. This indicated the retention of virulence in S0804 even after a prolonged period of storage, which may be due to higher retention of nutrient reserves by the nematode. The negligible level of reduction in virulence could perhaps be compensated using a slightly higher dose during the application.

The effect of EPN isolates was evaluated against RPW grubs in filter paper bioassay to find

Table 1. Virulence of fresh and 10 months old IJs of Steinernema sp. CPCRIS0804 against greater wax moth, Galleria mellonella

\begin{tabular}{|c|c|c|c|c|}
\hline \multirow[t]{2}{*}{ Treatments } & \multicolumn{4}{|c|}{$\begin{array}{c}\text { Percentage mortality of } \\
\text { G. mellonella }\end{array}$} \\
\hline & $\overline{12 H}$ & $24 \mathrm{H}$ & $36 \mathrm{H}$ & $\overline{48 H}$ \\
\hline 2.5 IJs larva ${ }^{-1}$ (Fresh) & $56.7^{\mathrm{a}}$ & $66.7^{\mathrm{bc}}$ & $70.0^{\mathrm{bc}}$ & $70.0^{\mathrm{bc}}$ \\
\hline 5 IJs larva $^{-1}$ (Fresh) & $70.0^{\mathrm{a}}$ & $86.7^{\mathrm{ab}}$ & $90.0^{\mathrm{ab}}$ & $93.3^{\mathrm{ab}}$ \\
\hline 10 IJs larva $^{-1}$ (Fresh) & $83.3^{\mathrm{a}}$ & $100.0^{\mathrm{ab}}$ & $100.0^{\mathrm{a}}$ & $100.0^{\mathrm{ab}}$ \\
\hline $2.5 \mathrm{IJs} \operatorname{larva}^{-1}$ (10 month old $)$ & $23.3^{\mathrm{b}}$ & $50.0^{\mathrm{c}}$ & $53.3^{\mathrm{c}}$ & $53.3^{\mathrm{c}}$ \\
\hline $5 \mathrm{IJs}$ larva $^{-1}$ (10 month old $)$ & $53.3^{\mathrm{ab}}$ & $73.3^{\mathrm{bc}}$ & $86.7^{\mathrm{ab}}$ & $86.7^{\mathrm{ab}}$ \\
\hline $10 \mathrm{IJs}$ larva $^{-1}$ (10 month old $)$ & $66.7^{\mathrm{a}}$ & $80.0^{\mathrm{ab}}$ & $83.3^{\mathrm{ab}}$ & $83.3^{\mathrm{ab}}$ \\
\hline Control & $0.0^{\mathrm{c}}$ & $0.0^{\mathrm{d}}$ & $0.0^{\mathrm{d}}$ & $\overline{0.0^{\mathrm{d}}}$ \\
\hline$\overline{\operatorname{LSD}(0.05)}$ & 19.5 & 21.5 & 21.1 & $\overline{20.4}$ \\
\hline
\end{tabular}




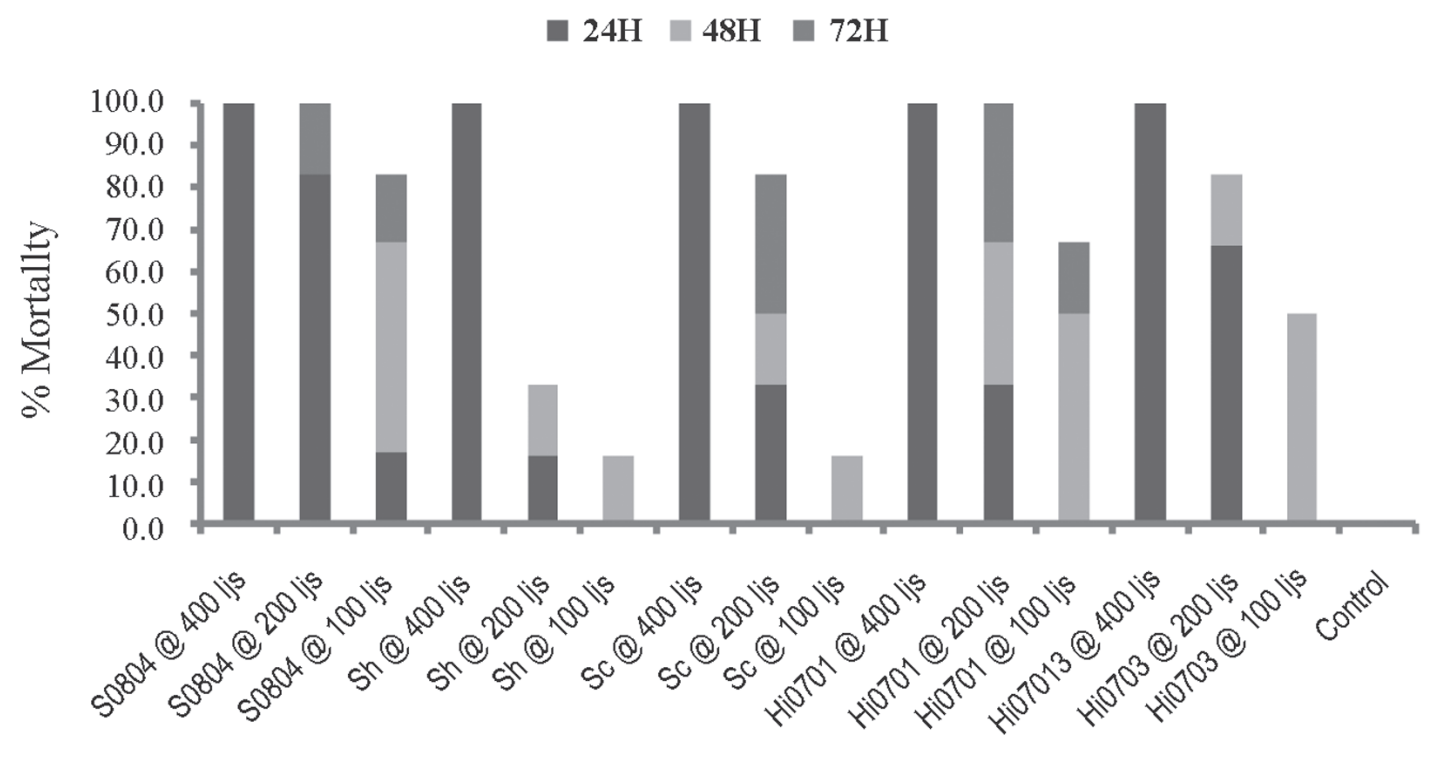

EPN species and doses used

Fig. 2. Comparative efficacy of different EPN isolates against red palm weevil. (S0804: Steinernema sp. CPCRIS0804; Sh: S. hermaphroditum CPCRIS0905; Sc: S. carpocapsae; Hi0701; H. indica CPCRIH0701; Hi0703: H. indica CPCRIH0703)

the most superior one, and the result is outlined in Figure 2.

All the isolates induced 100 per cent grub mortality within 24 hours at the exposed highest dose (400 IJs per grub) evaluated. Two of the isolates viz., S0804 and H0701, however, induced 100 per cent grub mortality even@200 IJs per grub after 72 hours of treatment application. More so, the grub mortality induced by S0804 was found the highest in all the doses at all the time intervals exposed. As the inoculum level of 200 IJs per grub could induce 100 per cent grub mortality in two of the isolates, three experiments were conducted using this dose as standard, for confirming the superiority of S0804. Mean mortality level induced by different EPN isolates in all the experiments were pooled together and presented in Table 2. The isolate, S0804 constantly yielded 100 per cent grub mortality in all the trials, whereas the mortality induced by all the other isolates varied from 70 to 90 per cent, thus asserting its superiority. Though the inter isolate variation in grub mortality was statistically insignificant, the isolate $\mathrm{S} 0804$ was rated as the best for the simple reason of inducing 100 per cent grub mortality, which is highly desirable and a prerequisite for employing against the destructive pest like RPW.

As the initial inoculum level of $200 \mathrm{IJs}$ per grub was found optimum inducing complete grub mortality in filter paper bioassay, double the dose (400 IJs per grub) was used in petiole bioassay by considering the possible loss of IJs during the host finding process. The grub mortality was 100 per cent when exposed with S0804, whereas, only 40 per cent grub mortality was observed in petioles treated with Sc within two weeks of treatment application (Fig. 3). In many instances, where S0804 treated, 100 per cent grub mortality was noticed within five days of superimposition of treatment. Delayed mortality induction was observed in those petioles where complicated tunnels were made by the grubs, and this could subsequently take more time for the IJs to locate the grubs.

Non-feeding and free-living third stage juveniles, known as IJs, are the appropriate stage of EPNs used as a successful biological agent and is the only survival stage in their life cycle. The success of any EPN species, therefore, depends on 
A new bio-control agent for the management of red palm weevil

Table 2. Comparative efficacy of different EPN isolates applied @ 200 IJs per grub against RPW. (S0804: Steinernema sp. CPCRIS0804; Sh: S. hermaphroditum CPCRIS0905; Sc: S. carpocapsae; Sa: S. abbasi; Hi0701: H. indica CPCRIH0701; Hi0703: H. indica CPCRIH0703)

\begin{tabular}{|c|c|c|c|c|c|c|}
\hline \multirow[t]{2}{*}{ EPN isolate } & \multicolumn{6}{|c|}{ Percentage mortality of RPW grubs } \\
\hline & $1 2 \longdiv { \text { HAT } }$ & 24 HAT & 36 HAT & 48 HAT & 60 HAT & 72 HAT \\
\hline S0804 & 0.0 & 50.0 & 83.3 & 90.0 & 90.0 & $100.0^{\mathrm{a}}$ \\
\hline Sh & 0.0 & 55.0 & 80.0 & 80.0 & 80.0 & $85.0^{\mathrm{ab}}$ \\
\hline $\mathrm{Sa}$ & 0.0 & 45.0 & 60.0 & 65.0 & 70.0 & $70.0^{\mathrm{b}}$ \\
\hline $\mathrm{Sc}$ & 0.0 & 50.0 & 80.0 & 90.0 & 90.0 & $90.0^{\mathrm{ab}}$ \\
\hline Hi0701 & 0.0 & 50.0 & 70.0 & 73.3 & 80.0 & $80.0^{\mathrm{ab}}$ \\
\hline Hi0703 & 0.0 & 30.0 & 55.0 & 66.7 & 75.0 & $75.0^{\mathrm{b}}$ \\
\hline Control & 0.0 & 0.0 & 0.0 & 0.0 & 0.0 & $0.0^{\mathrm{c}}$ \\
\hline LSD (0.05) & & 23.4 & 19.5 & 16.0 & 21.6 & 23.7 \\
\hline
\end{tabular}

Different alphabets in superscript represents statistically significant values

their ability to survive virulently till it finds a suitable host, which solely depends on the physiological and biochemical adaptations to conserve energy reserves for better survival and infectivity (Saheir and Ahmed, 2010; Gaugler, 1988). Besides, the quality and quantity of total lipid content within the nematode body is a major contributing factor towards high survival and virulence (Andalo et al., 2011). Therefore, all the formulation technologies are mainly aimed at minimizing the consumption of metabolic reserves during storage, which ultimately prolongs shelf life. The physiological activities of IJs are at a higher rate in elevated temperatures and minimum when exposed to low-temperature regimes (Andalo et al., 2011). Therefore, storage of EPNs at low temperatures is widely practiced for better survival of IJs in formulations. However, different EPN

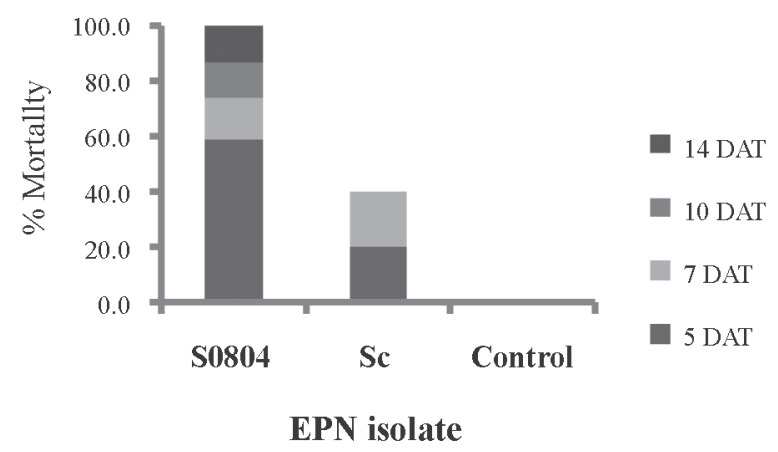

Fig. 3. Comparative efficacy of Steinernema sp. CPCRIS0804 and S. carpocapsae (@400 IJs per grub) against red palm weevil grubs in petiole bioassay, (DAT: Days after treatment) species are proved to be highly variable with regard to the optimum storage temperature (Strauch et al., 2000; Goud et al., 2010). The present study indicated a highly desirable characteristic feature of IJs of a local EPN species S0804 with regard to their ability to survive for a prolonged period without any additives under room temperature. The genetic potential of this species for better shelf life as compared to any other described species could be due to the presence of a high amount of lipid reserves coupled with their ability to preserve them for longer periods through reduced metabolism accomplished though less mobility. The lower survival rate of Heterorhabditids is attributed to the rapid depletion of lipid reserves in the IJs (Patel et al., 1997; Fitters et al., 1999). Due to slow utilization of lipid reserves in larger IJs, EPNs like $S$. feltiae and $S$. glaseri are reported to survive for a longer period as compared to those with smaller IJs like S. carpocapsae (Patel et al. 1997). In the present study, two of the species evaluated, namely Sh and S0804 are belonging to the glaseri group based on the molecular relationship and the sizes of their IJs are within the range of $S$. feltiae $(800-1000 \mu \mathrm{m})$ (Anes et al., 2018). Therefore, the comparatively larger size of this species could also be a contributing factor towards better shelf life.

Additionally, many EPN species are observed to minimize their activity in water suspension usually at lower temperatures, as a strategy to survive longer duration through reduced metabolism (Fitters and Griffin, 2004). The movement of S0804 in the water suspension was also observed to be less as compared to other 
species evaluated. The natural selection also acts on the EPNs when exposed to extremes of stress conditions which could lead to the survival of superior progenies with better adaptation like improved shelf life (Serwe-Rodriguez et al., 2004; Bornstein-Forst et al., 2005).

The local EPN isolate, S0804 was also found to be more virulent in terms of grub mortality over all the other species evaluated against RPW in both filter paper bioassay and petiole bioassay. In general, EPNs require a protective niche with a moist environment and are highly effective against insect pests of soil and cryptic habitat. Internal feeding habit coupled with the moist atmosphere within the feeding area makes EPN an ideal candidate against RPW. Over a period, several workers have evaluated different EPN species against RPW under laboratory as well as field conditions and reported mortality ranging from 36 to 100 per cent and in many of the studies $S$. carpocapsae was reported as the best candidate (Llácer et al., 2009; Manzoor et al., 2017). In the present investigation, also $S$. carpocapsae was observed to be the second-best performer against RPW. However, being a destructive pest, which infects the cabbage portion (growing point) of the palm, 100 per cent mortality of all the stages of RPW is essential for the complete recovery of the palm. In the present study, application of $4 \mathrm{~mL}$ water suspension containing 400 IJs of S0804 was observed to induce 100 per cent grub mortality in petiole bioassay which is a highly desirable characteristic feature when targeting a destructive pest like RPW. Besides, the efficient cruising behaviour of the IJs of this isolate was evident as the grubs which made complicated tunnels were also found infested, which was not noticed in the case of $S$. carpocapsae. Better adaptation of this native isolate to the prevailing agro-ecological conditions of the locality coupled with efficient cruising behaviour, could be the reasons for the superiority of this isolate (Koppenhöfer and Kaya, 1999).

The prolonged shelf-life together with better efficacy against RPW makes the isolate, $\mathrm{S} 0804$ a promising biocontrol agent for the management of RPW. Prophylactic as well as curative treatment through an effective delivery mechanism of this EPN species (Steinernema sp. S0804) will be targeted in coming days as a biological suppressant of RPW.

\section{Conclusion}

Local EPN isolate Steinernema sp. CPCRIS0804 possessed natural fitness ability to survive for longer duration at ambient temperature. Presence of live IJs of this isolate up to $13^{\text {th }}$ month and desirable level of survival up to 10 months of storage without any significant reduction in virulence is the superiority of this species. This is the first report of long duration survival of any EPN under ambient temperature without the intervention of any formulation technology and offers a practical solution for difficulties encompassed due to poor shelf life in all the described species. Fortunately, this isolate was also found to be superior among all the other species evaluated against RPW, which is a destructive pest of international importance, against which no biocontrol agent is so far successful. Better shelf life, coupled with high pathogenicity make this isolate an ideal candidate for the bio-suppression of RPW infesting coconut. The correct identity of this isolate needs to be established as it did not group with any other described species (maximum of only 92 per cent identity with $S$. hermaphroditum) and therefore, presumed to be a new species for identification (Anes et al., 2018). The future research will also be focused on developing successful field delivery mechanisms for the utilization of this EPN isolate in prophylactic as well as a curative mode as an effective eco-friendly strategy against RPW.

\section{References}

Andalo, V., Moino, A. Jr., Maximiniamo, C., Campos, V.P. and Mendonca, L.A. 2011. Influence of temperature and duration of storage on the lipid reserves of entomopathogenic nematodes. Revista Colombiana de Entomologia 37(2): 203-209.

Anes, K.M., Merin B., Jinu, S. and Josephrajkumar, A. 2018. New distribution record of Steinernema hermaphroditum (Rhabditida: Steinernematidae) from Kerala, India. Indian Journal of Nematology 48(2): 69-177.

Banu, J.G., Rajendran, and G., Subramanian, S. 2003. Susceptibility of red palm weevil, Rhynchophorus ferrugineus (Olivier) to entomopathogenic nematodes. Annals of Plant Protection Sciences 11: 104-106. 
Bedding, R.A. 1990. Logistics and strategies for introducing entomopathogenic nematode technology in developing countries. In: Entomopathogenic Nematodes in Biological Control. (Eds.) Gaugler, R. and Kaya, H.K. CRC Press, Boca Raton. pp. 233-248.

Bornstein-Forst, S., Kiger, H. and Rector, A. 2005. Impacts of fluctuating temperature on the development and infectivity of entomopathogenic nematode Steinernema carpocapsae A10. Journal of Invertebrate Pathology 88(2): 147-153.

Chen, S. and Glazer, I. 2005. A novel method for longterm storage of the entomopathogenic nematode Steinernema feltiae at room temperature. Biological Control 32: 104-110.

Fitters, P.F.L. and Griffin, C.T. 2004. Spontaneous and induced activity of Heterorhabditis megidis infective juveniles during storage. Nematology 6(6): 911-917.

Fitters, P.F.L., Patel, M.N., Griffin, C.T. and Wright, D.J. 1999. Fatty acid composition of Heterorhabditis sp. during storage. Comparative Biochemistry and Physiology 124(8): 81-88.

Gaugler, R. 1988. Ecological consideration in the biological control of soil inhabiting insect pests with entomopathogenic nematodes. Agricultural Ecosystem and Environment 24: 351-360.

Goud, S., Huger, P.S. and Prabhuraj, A. 2010. Effect of temperature, population density and shelf life of EPN Heterorhabditis indica (RCR) in sodium alginate gel formulation. Journal of Biopesticides 3(3): 627-632.

Grewal, P.S. 2000. Anhydrobiotic potential and long-term storage of entomopathogenic nematodes (Rhabditida: Steinernematidae). International Journal for Parasitology 30(14): 995-1000.

Grewal, P.S. 2002. Formulation and application technology. In: Entomopathogenic Nematology. (Ed.) Gaugler, R. CABI Publishing, Wallingford, U.K. pp. 265-288.

Griffin, C.T. 1993. Temperature responses of entomopathogenic nematodes for the success of biological control programs. In: Nematodes and the Biological Control of Insect Pests. (Eds.) Bedding, R., Akhurst, R. and Kaya, H. CSIRO Publications, East Melbourne, Australia. pp. 101-111.

Josephrajkumar, A., Mohan, C., Thomas, S., Namboothiri, C.G.N., Shanavas, M. 2014. Subduing red palm weevil attack on coconut through fine-tuned management approaches. In: Book of Abstracts National Conference on Sustainability of Coconut, Arecanut and Cocoa Farming Technological Advances and Way Forward. (Eds.) Muralidharan, K., Rajesh, M.K., Muralikrishna, K.S., Vijayan, J., Jeyaskhar, S. ICAR-CPCRI, Kasaragod. pp. 86.

Josephrajkumar, A., Mohan, C., Prathibha, P.S., Rajkumar, Nalinakumari, T. and Nair, C.P.R. 2018. Pest dynamics and suppression strategies. In: The Coconut Palm (Cocos nucifera L.) - Research and development perspectives. (Eds.) Nampoothiri, K.U.K., Krishnakumar, V., Thampan, P.K. and Nair, M.A. Springer Nature Singapore Pvt. Ltd. pp. 557-634.
Josephrajkumar, A., Prathibha, P.S., Merin, B., Mohan, C., Hegde, V., Krishnakumar, V. and Chowdappa, P. 2017. Red Palm Weevil in Coconut-Knack to Crack Trajectory. ICAR-CPCRI, Regional Station, Kayamkulam. 28 p.

Kagimu, N., Ferreira, T. and Malan, A. 2017. The attributes of survival in the formulation of entomopathogenic nematodes utilised as insect biocontrol agents. African Entomology 25: 275-291.

Kaya, H.K. 1990. Soil ecology. In: Entomopathogenic Nematodes in Biological Control. (Eds.) Gaugler, R. and Kaya, H.K. CRC Press, Boca Raton, FL. pp. 93-115.

Koppenhöfer, A.M. and Kaya, H.K. 1999. Ecological characterization of Steinernema rarum. Journal of Invertebrate Parasitology 73: 120-128.

Koppenhöfer, A.M. 2007. Nematodes. In: Field Manual of Techniques in Invertebrate Pathology: Application and Evaluation of Pathogens for Control of Insects and Other Invertebrate Pests, Second edn. (Eds.) Lacey, L.A. and Kaya, H. K. Springer, Dordrecht. pp. 249-264.

Llácer, E., Martínez, D., Altube, M.M. and Jacas, J.A. 2009. Evaluation of the efficacy of Steinernema carpocapsae in a chitosan formulation against the red palm weevil, Rhynchophorus ferrugineus, in Phoenix canariensis. BioControl. 54: 559-565.

Malumphy, C. and Moran, H. 2009. Red palm weevil, Rhynchophorus ferrugineus. Plant Pest Fact Sheet. http:/ /www.defra.gov.uk/fera/plants/plant.

Manzoor, M., Ahmad, J.N., Sharif, M.Z., Majeed, D., Kiran, H., Jafir, M. and Ali, H. 2017. Comparative effectiveness of entomopathogenic nematodes against red palm weevil (Rhynchophorus ferrugineus) in Pakistan. Journal of Entomology and Zoology Studies. 5(5): 756-60.

Patel, M.N., Stolinski, M. and Wright, D.J. 1997. Neutral lipids and the assessment of infectivity in entomopathogenic nematodes: Observations on four Steinernema species. Parasitology 114: 489-496.

Rao, V.P. and Manjunath, T.M. 1966. DD-136 nematode that can kills many insect pests. Indian Farming 16: 43-44.

Saheir, F. and Ahmed, A. 2010. Physiological and biological studies of some entomopathogenic nematode species of families (Steinernematidae and Heterorabditidae). Egyptian Academic Journal of Biological Sciences C, Physiology and Molecular Biology 2: 45-54.

Serwe-Rodriguez, J., Sonnenberg, K., Appleman, B. and Bornstein-Forst, S. 2004. Effects of in host desiccation on development, survival, and infectivity of entomopathogenic nematode Steinernema carpocapsae. Journal of Invertebrate Pathology 85(3): 175-181.

Shamseldean, M.M. and Atwa, A.A. 2004. Virulence of Egyptian Steinernematid nematodes used against the red palm weevil, Rhynchophorus ferrugineus (Oliv.). Egyptian Journal of Biological Pest Control 14: 135-140.

Strauch, O., Niemann, I., Neumann, A., Schmidt, A.J., Peters, A. and Ehlers, R.U. 2000. Storage and formulation of the entomopathogenic nematodes Heterorhabditis indica and H. bacteriophora. Biocontrol 45: 483-500. 